\title{
Bone formation without lamina dura in the middle-aged and elderly: possible dependence on enamel
}

This article was published in the following Dove Press journal:

Clinical Interventions in Aging

24 February 2010

Number of times this article has been viewed

\author{
Minoru Yamaoka' \\ Masahide Ishizuka' \\ Kohji Ishihama' \\ Masahiro Takahashi' \\ Miho Takahashi' \\ Hidefumi Yamada' \\ Yuji Teramoto' \\ Kouichi Yasuda' \\ Toshikazu Shiba ${ }^{2}$ \\ Takashi Uematsu' \\ Kiyofumi Furusawa' \\ 'Matsumoto Dental University, Oral \\ and Maxillofacial Surgery, Shiojiri, \\ Nagano, Japan; ${ }^{2}$ Regenetiss \\ Co., Koganei, Tokyo, Japan
}

\begin{abstract}
Bone formation below the crown of mandibular horizontal incompletely impacted third molar is frequently seen in the middle-aged and elderly. The phenomenon shows lamina dura loss without radiolucency and we hypothesized the participation of mature enamel without any influence on the environmental oral status. In order to investigate the characteristics of the phenomenon based on the presence/absence of the lamina dura and radiolucency below the crown, we studied the relationship between 58 men and 43 women with a lamina dura without radiolucency, 12 men and 8 women without a lamina dura with radiolucency, 34 men and 16 women without a lamina dura without radiolucency, and the status of teeth in the ipsilateral mandible. Subjects without a lamina dura without radiolucency were significantly older than those with a lamina dura without radiolucency in both men $(P<0.0001)$ and women $(P<0.01)$, indicating different chronological causes. Men without lamina dura with radiolucency showed significantly more tooth loss than those with a lamina dura without radiolucency $(P<0.00001)$ and those without a lamina dura without radiolucency $(P<0.0001)$, indicating the influence of poor oral health. Thus, the phenomenon without a lamina dura without radiolucency may show the clinical importance of bone formation in the elderly.
\end{abstract}

Keywords: bone formation, lamina dura, enamel, elderly

\section{Introduction}

Bone formation below the crown of mandibular horizontal incompletely impacted third molar on radiograph is frequently seen in the middle-aged and elderly. The phenomenon shows lamina dura loss without radiolucency below the crown. Tooth germ has a thick lamina dura with a broad space between the crown and the surface of alveolar bone. Since bone formation is generally seen accompanying bone modeling in young individuals, the deposition of bone gradually reduces the space between the crypt wall and the tooth to the dimensions of the periodontal ligaments. ${ }^{1}$ After bone growth, remodeling by balancing osteoblasts and osteoclasts is regulated as homeostasis in the volume of bone; however, remodeling does not prevent skeletal aging after the third decade of life, resulting in decreased bone mass. ${ }^{2}$ Moreover, bone resorption is affected with local factors, including inflammation and mechanical forces, malignant tumor, and administration of bisphosphonate and hormones. However, we have identified bone formation, from which it is difficult to discern the space from the enamel surface below the crown of mandibular incompletely impacted third molars in middleaged and elderly individuals, ${ }^{3}$ and discussed the mechanism of occurrence, ${ }^{4}$ whereas an apparent space between the crown and bone with lamina dura was seen in young healthy individuals. Local factors in the mouth, except ipsilateral tooth loss, did not
Correspondence: Minoru Yamaoka Matsumoto Dental University, Oral and Maxillofacial Surgery, Shiojiri, Nagano 399-078I, Japan

Tel +8I 263512075

Fax +81263512076

Email yamaoka@po.mdu.ac.jp 
seem to influence bone formation without the lamina dura in the space in elderly men; that is, bone below the crown seems to arise from alveolar bone, although the reason why the space is filled with bone formation without a lamina dura in the middle-aged and elderly is unknown. This phenomenon may be crucial for maintaining teeth.

In events during enamel maturation, death of ameloblasts occurs during the maturation stage of amelogenesis, ${ }^{5,6}$ and is defined as apoptotic death, ${ }^{7,8}$ which lasts until eruption, when the epithelium of the enamel organ fuses with the oral epithelium. ${ }^{9}$ Maturing enamel loses organic content, ${ }^{10}$ accompanied with a decrease in the function of proteinases and degradation of proteins secreted into enamel, ${ }^{11}$ the peak of which occurs in the maturation stage. ${ }^{12}$ Thus, ameloblasts may be a source of the proteinases digesting matrix protein in enamel. ${ }^{13} \mathrm{We}$ hypothesized that mature enamel after protein loss might not reject bone and fills the space below the crown rather than a high activity of bone tissue in the elderly, whereas proteins secreted from ameloblasts may inhibit bone formation during eruption. We then studied the third molar with radiolucency without a lamina dura below the crown comparing with that with a lamina dura without radiolucency and that without a lamina dura without radiolucency to assess these characteristics and the effects of local factors. This provides a foundation for understanding the cause of bone formation in the third molar independently of the oral environment. We report the clinical importance of this bone formation, which is probably derived from mesenchymal tissue in the absence of cement and periodontium, especially in the middle-aged and elderly.

\section{Methods}

Orthopantomographs were examined in 104 teeth from 88 men and 67 teeth from 58 women who had horizontal incompletely impacted third molars at the initial examination for diagnosis and treatment between January 1988 and December 1995 at Matsumoto Dental University Hospital, Oral and Maxillofacial Surgery (Table 1). The mean age \pm standard deviation (SD) of 88 men was $48.93 \pm 13.59$ (range, 31-89 years), and that of 58 women was $41.93 \pm 9.46$ (range, 31-75 years). Horizontal incompletely impacted third molars, in which the crown is partly at the level of the alveolar bone ridge, were monitored regarding the lamina dura and radiolucency below the crown of the tooth to the cementoenamel junction. The status of a horizontal incompletely impacted third molar was confirmed with orthopantomographs taken with a Panoramax Auto $20 \mathrm{~mA}, 80-84$ $\mathrm{kVp}$ (Asahi, Kyoto, Japan) and the films were processed in an automatic developing machine (Konica SRX-501; Konica, Tokyo, Japan). Incompletely impacted third molars were horizontal to the second molar in angulation and were not fully covered with bone. Horizontal angulation was measured using horizontal lines drawn at various heights at the occlusal plane of the second molar ${ }^{14}$ or the first molar when the second molar was lost, or the premolar when the second and first molars were lost. The inclination of the occlusal plane of the third molar was read from the line on a compass. Teeth with inclinations of $70^{\circ}$ or greater were selected as horizontal angulation following Shiller. ${ }^{14}$ Radiograms were measured twice by the same experienced oral surgeon. The second measurement was performed after a period of months without seeing primary data. Teeth with an inclination of $69^{\circ}$ or smaller on either measurement were excluded from the study. Teeth were classified into three groups based on the presence/absence of the radiolucency and the lamina dura below the crown of the horizontal incompletely impacted third molar, and analyzed by comparing these groups. Out of three groups, one was the third molar with lamina dura without radiolucency (Figure 1), one without a lamina dura with radiolucency (Figure 2), and one without a lamina dura without radiolucency (Figure 3). Radiolucency and the lamina dura were assessed by visual observation at $2 \times$ magnification. Measurements of the presence/absence of radiolucency and the lamina dura were performed twice by an experienced oral surgeon. Radiolucency below the crown was defined by a diffuse lucent area due to irregular widening of follicular space, ranging in width from 0 to $3.5 \mathrm{~mm}$ in maximum amount below the crown. The presence of the lamina dura below the crown was defined

Table I Number of teeth with and without a lamina dura and radiolucency

\begin{tabular}{lllll}
\hline Age (y.) & $\begin{array}{l}\text { No of teeth } \\
\text { with lamina } \\
\text { dura } \\
\text { without } \\
\text { radiolucency }\end{array}$ & $\begin{array}{l}\text { No of teeth } \\
\text { without } \\
\text { lamina dura } \\
\text { with } \\
\text { radiolucency }\end{array}$ & $\begin{array}{l}\text { No of teeth } \\
\text { without } \\
\text { lamina dura } \\
\text { without } \\
\text { radiolucency }\end{array}$ & Total \\
\hline Men & & & & \\
3 I-40 & 33 & 6 & 4 & 43 \\
4 I-50 & 13 & 1 & 15 & 29 \\
$\geq 5$ I & 12 & 5 & 15 & 32 \\
Total & 58 & 12 & 34 & 104 \\
Women & & & & \\
3 I-40 & 29 & 6 & 4 & 39 \\
4 I-50 & 11 & 0 & 6 & 17 \\
$\geq 5$ I & 3 & 2 & 6 & 11 \\
Total & 43 & 8 & 16 & 67 \\
\hline
\end{tabular}




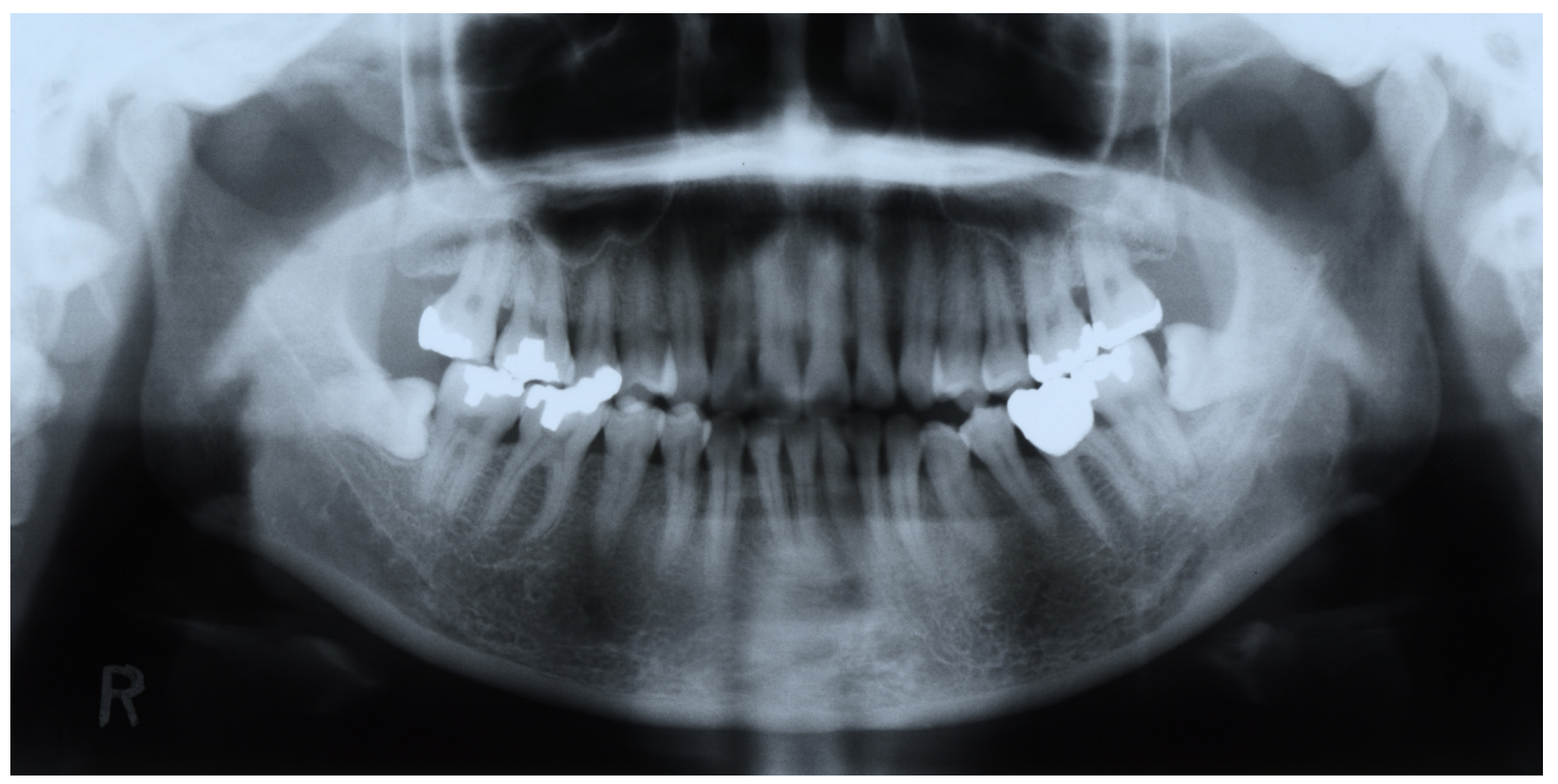

Figure I Right horizontal incompletely impacted third molar with lamina dura without radiolucency below the crown in a 38-year-old woman.

by a fully or partly uniform line as still present, even if the line was partly irregularly ruptured. Absence of the lamina dura was defined as no detection of a white line below the crown. On the other hand, the degree of bone resorption at the mesial surface of the canine and the first molar was assessed for aging or periodontal disease. Exposure of the root surface of the teeth was measured from the cementoenamel junction to the alveolar crest at the mesial site of the teeth, and exposure of the root surface was calculated as a fraction of the root length as determined radiographically. The mean \pm SD rate of bone resorption between the first and second measurements in the canine and first molar was calculated, with the mean \pm SD in those teeth in relation to the ipsilateral third molar, and grouped into categories with or without the lamina dura and the radiolucency below the crown of the third molar. Imperfect views of the root because of imbrication of individual roots due to curvature of the dental arch were excluded from the assessment. When assessment of

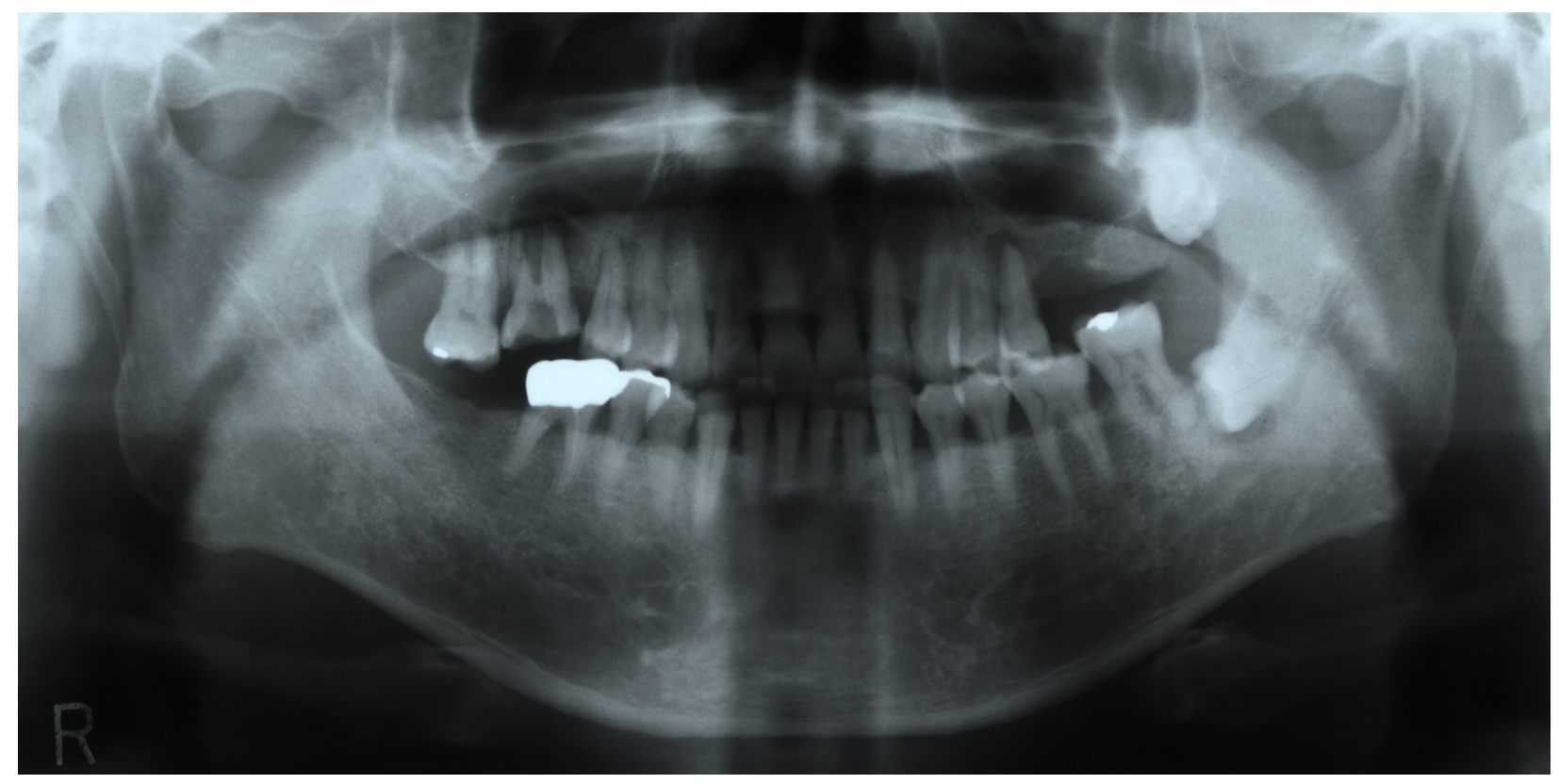

Figure 2 Left horizontal incompletely impacted third molar without lamina dura with radiolucency below the crown in a $5 \mathrm{I}$-year-old man. 


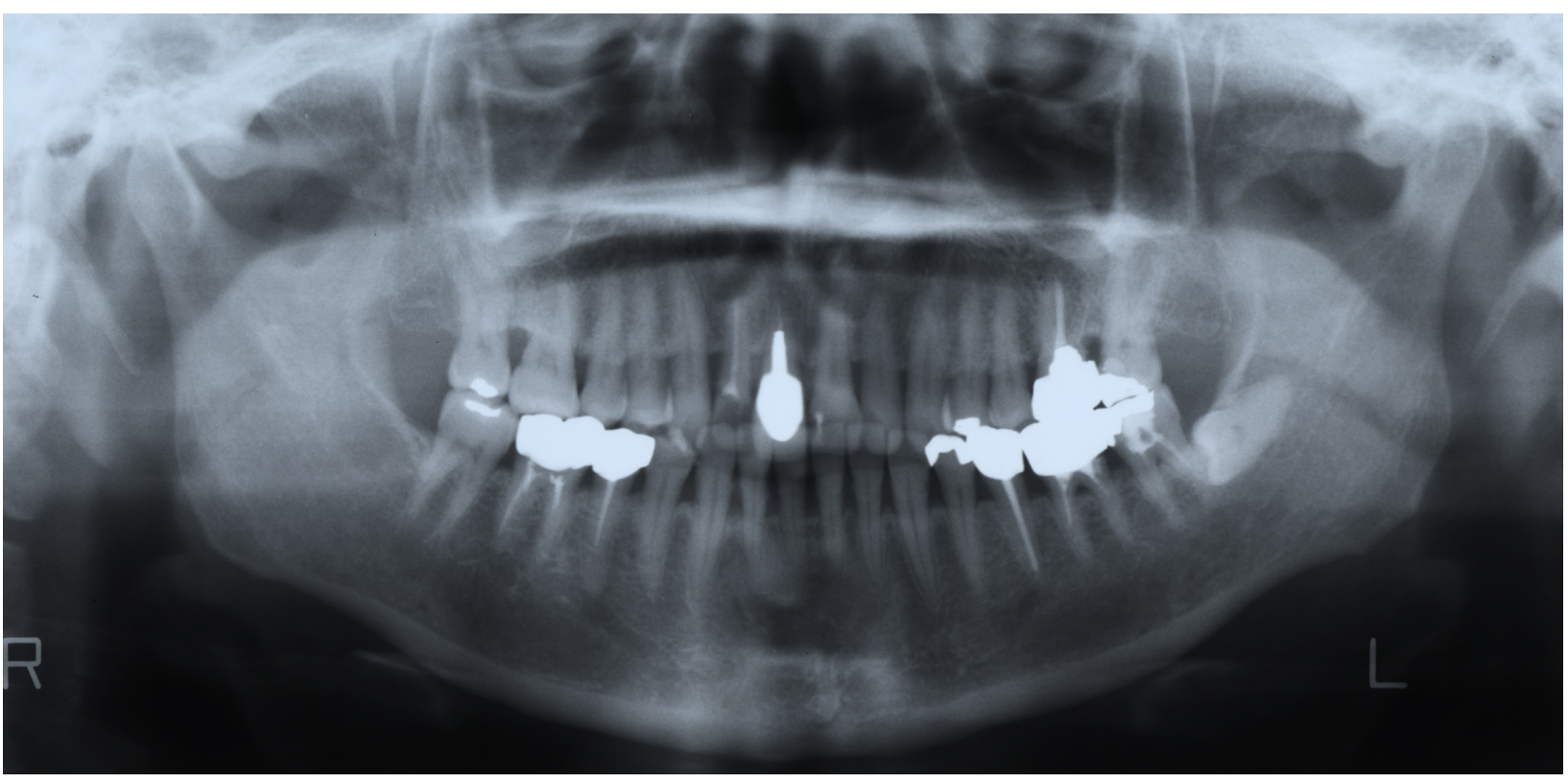

Figure 3 Left horizontal incompletely impacted third molar without lamina dura without radiolucency below the crown in a 53-year-old woman.

the presence or absence of radiolucency or lamina dura was different between the first and second measurements, this was also excluded from the study. Patients with an apical lesion at the root of the mandibular second or third molar, a radiographically true cyst or tumor in the mandible, diffuse radiolucency below the crown, a completely impacted third molar, vertical impaction or distoangular impaction, and a restoration ending below the cementoenamel junction of the second molar were excluded from analysis.

\section{Statistical analysis}

Rates of teeth with and/or without a lamina dura and/or radiolucency and the ages of patients were calculated and analyzed statistically using Student's $t$-test, Fisher's $t$-test, or $\chi^{2}$ analysis among these groups.

\section{Results}

Fifty-eight teeth with a lamina dura without radiolucency, 12 teeth without a lamina dura with radiolucency, and 34 teeth without a lamina dura without radiolucency in men, and 43 teeth with a lamina dura without radiolucency, 8 without a lamina dura with radiolucency, and 16 without a lamina dura without radiolucency in women were seen in subjects with a mandibular horizontal incompletely impacted third molar (Table 1). We observed that the group with a lamina dura without radiolucency was significantly younger than the group without a lamina dura without radiolucency in men $(P<0.0001)$ and women $(P<0.01)$, and younger than the group without a lamina dura with radiolucency in men $(P<0.05)$ (Table 2). Alveolar bone resorption in the canine and first molar region could be assessed in 49 teeth with a lamina dura without radiolucency in men, 8 without a lamina dura with radiolucency in men, 28 without a lamina dura without radiolucency in men, 39 teeth with a lamina dura without radiolucency in women, 7 without a lamina dura with radiolucency, and 16 without a lamina dura without radiolucency. Alveolar bone resorption in the canine and first molar regions in subjects was not different between these groups. Tooth loss in men was significantly higher in the group without a lamina dura with radiolucency than with a lamina dura without radiolucency $(P<0.00001)$, and without a lamina dura without radiolucency $(P<0.0001)$. For other measures of tooth loss in women, the number of teeth treated with metal repair, and the number of decayed teeth in the ipsilateral mandible, there were no significant associations between these three groups.

\section{Discussion}

Our results show that men with a lamina dura without radiolucency were younger than those without a lamina dura with radiolucency and without a lamina dura without radiolucency, and women with a lamina dura without radiolucency were younger than women without a lamina 
Table 2 Lamina dura and radiolucency and status of bone and teeth on ipsilateral side

\begin{tabular}{|c|c|c|c|}
\hline Men & $\begin{array}{l}\text { With lamina dura without } \\
\text { radiolucency ( } 58 \text { teeth) }\end{array}$ & $\begin{array}{l}\text { Without lamina dura with } \\
\text { radiolucency ( } 12 \text { teeth) }\end{array}$ & $\begin{array}{l}\text { Without both lamina dura } \\
\text { and radiolucency ( } 34 \text { teeth) }\end{array}$ \\
\hline Age (y.) & $42.76 \pm 10.48(58)^{\mathrm{a}, \mathrm{b}}$ & $51.92 \pm 19.33(12)^{\mathrm{a}}$ & $53.06 \pm 12.68(34)^{b}$ \\
\hline $\begin{array}{l}\text { Bone resorption in the canine } \\
\text { and first molar }\end{array}$ & $0.08 \pm 0.09(49)$ & $0.17 \pm 0.28(8)$ & $0.07 \pm 0.08$ \\
\hline No of teeth loss & $25 / 406(6.2 \%)^{c}$ & $20 / 84(23.8 \%)^{c, d}$ & $17 / 238(7.1 \%)^{d}$ \\
\hline $\begin{array}{l}\text { No of teeth treated with } \\
\text { metal repair }\end{array}$ & II5/38I (30.2\%) & $16 / 68(23.5 \%)$ & 65/221 (29.4\%) \\
\hline No of decayed teeth & $6 / 381$ (1.6\%) & $1 / 68(1.5 \%)$ & $4 / 221$ (1.8\%) \\
\hline Women & $\begin{array}{l}\text { With lamina dura without } \\
\text { radiolucency } \\
\text { (43 teeth) }\end{array}$ & $\begin{array}{l}\text { Without lamina dura with } \\
\text { radiolucency } \\
(8 \text { teeth })\end{array}$ & $\begin{array}{l}\text { Without both lamina dura } \\
\text { and radiolucency ( } 16 \text { teeth) }\end{array}$ \\
\hline Age (y.) & $39.49 \pm 8.37(43)^{\mathrm{e}}$ & $41.25 \pm 10.38(8)$ & $46.69 \pm 9.35(16)^{\mathrm{e}}$ \\
\hline \multicolumn{2}{|c|}{$\begin{array}{l}\text { Bone resorption in the canine and first } 0.02 \pm 0.06 \text { (39) } \\
\text { molar }\end{array}$} & $0.04 \pm 0.07(7)$ & $0.02 \pm 0,07(16)$ \\
\hline No of teeth loss & $|4 / 30|(4.7 \%)$ & $1 / 56(1.8 \%)$ & $2 / 112(1.8 \%)$ \\
\hline $\begin{array}{l}\text { No of teeth treated with } \\
\text { metal repair }\end{array}$ & I I 4/287 (39.7\%) & 19/55 (34.5\%) & $42 / 110$ (38.2\%) \\
\hline No of decayed teeth & $5 / 287(1.7 \%)$ & $1 / 55(1.8 \%)$ & $2 / 110(1.8 \%)$ \\
\hline
\end{tabular}

a $P<0.05,{ }^{b, d} p<0.0001,{ }^{c} P<0.00001,{ }^{e p}<0.01$

dura without radiolucency. Tooth loss was higher in men without a lamina dura with radiolucency than in men with a lamina dura without radiolucency, and without a lamina dura without radiolucency. This indicates that the presence of probable chronic inflammation, shown in men without a lamina dura with radiolucency, may be discerned from sound radiographic findings in men with a lamina dura without radiolucency and without a lamina dura without radiolucency, and teeth without a lamina dura without radiolucency may remain relatively constant until middle and older age, whereas teeth with a lamina dura without radiolucency are seen in young subjects. In subjects with chronic inflammation without a lamina dura with radiolucency, SD in age was greater than in the other two groups in both genders. This may strengthen the thought that teeth without a lamina dura without radiolucency can arise independently of the conditions around the third molar in men and probably women. Moreover, increased teeth loss in men may be possibly related to poor oral health, ${ }^{15,16}$ although this could not be assessed in this study.

Thus, bone formation without a lamina dura below the crown is independent of the oral status in ipsilateral teeth, and arises from alveolar bone. The third molar may, as the occasion demands, maintain the status of a lamina dura without radiolucency, or become with radiolucency without a lamina dura, and develop to the status with bone formation without lamina dura with aging. Although the progress is unclear, this may be based on homeostasis, local stimuli, such as inflammation, or apoptosis of enamel below the crown in the third molar.

The finding that bone formation reduces the space between the alveolar bone and the crown below the third molar in the middle-aged and elderly, although it is unclear whether specifically coupled enamel/bone exchange is seen, radiographically differed from bone resorption normally regulating eruption in the young and bone resorption in aging. This suggests that new bone forms after homeostastic mechanisms fail.

Bone production is suppressed during enamel formation, resulting in burgeoning accompanied by bone resorption. Enamelysin (matrix metalloproteinase [MMP]) ${ }^{13}$ degrades amelogenin,${ }^{17}$ eliminates enamel matrix proteins, ${ }^{18}$ facilitates replacement of the organic matrix with minerals, ${ }^{19}$ and processes amelogenin during the secretory stage, ${ }^{20}$ although bone resorption in tooth eruption is seen associated with the expression of osteoprotegerin..$^{21}$ Reduced enamel secretion due to apoptosis may also drive bone production. After enamel maturation is complete, the entire enamel organ is greatly reduced. ${ }^{22}$ Thus, apoptosis of enamel is essential for eruption, and bone formation below the crown may be induced by a decline in enamel activities. This suggests that enamel matrix protein (EMD), which is extracted from fetal porcine tooth germs and contains enamel proteins 
of amelogenin and ameloblastin etc. ${ }^{23-25}$ cannot exclude the suppression of bone production. Moreover, EMD may function in ectomesenchymal tissue, whereas apoptotic mature enamel may help mesenchymal tissue.

Apoptosis in ameloblasts of the erupting molar tooth is temporarily seen as part of the reduced dental epithelium. Accompanying eruption, apoptotic reactions are no longer seen in the remainder of the reduced ameloblasts. ${ }^{9}$ Progressively decreased enamel secretion can show a sustained increase in bone production. In consequence, the border of tooth and bone, which is generally interstratified by periodontium or connective tissue, can become closer with aging. Delays or prevention of eruption in horizontal incompletely impacted third molar may arise from bone formation below the crown in the middle-aged and elderly as the controlling mechanisms of the final condition without any stimuli, such as inflammation. This may provide a clue to comprehend complex signaling in the periodontium or periostium, and diseases involving the membranes. Ten Cate $^{26}$ noted that the origin of new bone formed at the time of periodontal ligament organization might develop from the layer of ectomesenchymal cells investing the tooth germ, and the dental follicle is the formative organ for tooth support tissues. However, the bone formation in the current study may be caused by a different mechanism arising from the surface of alveolar bone without periodontium and cement. Radiographic findings show that enamel contributes to bone formation and that dead enamel can be used to induce bone formation by intervening in bone loss. The phenomenon that apoptotic enamel loses protein and proteinase activities lead to bone formation seems to have an unanticipated role in strengthening bone in the elderly. Recently, peak thickness in subjects aged 40 to 49 years was reported in mandibular cortical bone, ${ }^{27}$ but data was not identified in the third molar. We doubt if the increased thickness of cortical bone may be absent of lamina dura.

In conclusion, this concept of close contact with enamel due to dead enamel could be extended to clinical applications using material which shares certain characteristics of matured enamel captured by dead amelogenin. Further exploration in animal trials should obtain sufficient evidence to determine the superiority of mature enamel with respect to bone formation. Evaluating the usefulness of enamel is therefore a future challenge.

\section{Disclosures}

The authors report no conflicts of interest in this work.

\section{References}

1. Ten Cate AR. Oral Histology: Development, structure, and function. 4th ed. St. Louis, MO: Mosby; 1994:267-268.

2. Glowacki J. The deceiving appearances of osteoclasts. $N$ Engl J Med. 2009;360(1):80-82.

3. Yamaoka M, Takahashi M, Ishihama K, Uematsu T, Furusawa K. Age-related disruption of lamina dura: Evidence in the mandibular horizontal incompletely impacted third molar. Clin Interv Aging. 2009;4:451-456.

4. Yamaoka M, Ishizuka M, Takahashi M, Uematsu T, Furusawa K. Bone formation with disruption of the lamina dura in the third molar. Clinical Cosmetic and Investigational Dentistry. 2010;2:1-3.

5. Moe H, Jessen H. Phagocytosis and elimination of amelocyte debris by stratum intermedium cells in the transitional zone of the enamel organ of the rat incisor. Z Zellforsch. 1972;131(1):63-75.

6. Smith CE, Warshawsky H. Quantitative analysis of cell turnover in the enamel organ of the rat incisor, evidence for ameloblast death immediately after enamel matrix secretion. Anat Rec. 1977;187(1):63-98.

7. Kroemer G, Petit P, Zamzami N, Vayssiěre JL, Mignotte B. The biochemistry of programmed cell death. FASEB J. 1995;9(13): 1277-1287.

8. Patel T, Gores GJ, Kaufmann SH. The role of proteases during apoptosis. FASEB J. 1996;10(5):587-597.

9. Shibata S, Suzuki S, Tengan T, Yamashita Y. A histochemical study of apoptosis in the reduced ameloblasts of erupting mouse molars. Arch Oral Biol. 1995;40(7):677-680.

10. Nanci A, Slavkin HC, Smith CE. Application of high-resolution immunocytochemistry to the study of the secretory, resorptive, and degradative functions of ameloblasts. Adv Dent Res. 1987;1(2):148-161.

11. Smith CE, Nanci A. Protein dynamics of amelogenesis. Anat Rec. 1996;245(2):186-207.

12. Overall $\mathrm{CM}$, Limebach $\mathrm{H}$. Identification and characterization of enamel proteinases isolated from developing enamel. Biochem $\mathrm{J}$. 1988;256(3):965-972.

13. Bartlett JD, Simmer JP, Xue J, Margolis HC, Moreno EC. Molecular cloning and mRNA tissue distribution of a novel matrix metalloproteinase isolated from porcine enamel organ. Gene. 1996;183(1-2): 123-128.

14. Shiller WR. Position changes in mesioangular impacted third molars during a year. J Am Dent Assoc. 1979;99(3):460-464.

15. Slade GD, Gansky SA, Spencer AJ. Two-year incidence of tooth loss among South Australians 60+ years. Community Dent Oral Epidemiol. 1997;25(6):429-437.

16. Ericsson J, Abrahamsson KH, Östberg AL, Hellström MK, Jönsson K, Wennström JL. Periodondontal health status in Swedish adolescents: an epidemiological, cross-sectional study. Swed Dent J. 2009;33(3): 131-139.

17. Bartlett JD, Ryu OH, Xue J, Simmer JP, Margolis HC. Enamelysin mRNA displays a developmentally defined pattern of expression and encodes a protein which degrades amelogenin. Connect Tissue Res. 1998;39(1-3):101-109.

18. Simmer JP, Hu JC. Expression, structure, and function of enamel proteinases. Connect Tissue Res. 2002;43(2-3):441-449.

19. Lu Y, Papagerakis P, Yamakoshi Y, Hu JC, Bartlett JD, Simmer JP. Functions of KLK4 and MMP-20 in dental enamel formation. Biol Chem. 2008;389(6):695-700.

20. Nagano T, Kakegawa A, Yamakoshi Y, et al. Mmp-20 and Klk4 cleavage site preferences for amelogenin sequences. $J$ Dent Res. 2009;88(9):823-828.

21. Nanci A. Ten Cates Oral Histology: Development, Structure, and Function. 7th ed, St. Louis, MO: Mosby; 2008:273.

22. Robinson C, Kirkham J, Shore R. Dental Enamel. Formation to Destruction. New York, NY: CRC Press; 1995:49.

23. Brookes SJ, Robinson C, Kirkham J, Bonass WA. Biochemistry and molecular biology of amelogenin proteins of developing dental enamel. Arch Oral Biol. 1995;40(1):1-14. 
24. Kresbach PH, Lee SK, Matsuki Y, Kozak CA, Yamada Y. Full-length sequence, localization, and chromosomal mapping of ameloblastin. J Biol Chem. 1996;271(8):4431-4435.

25. Cerny R, Slaby I, Hammarström L, Wurtz T. A novel gene expressed in rat ameloblasts codes for proteins with cell binding domains. $J$ Bone Miner Res. 1996;11(7):883-891.
26. Ten Cate AR. Formation of supporting bone in association with periodontal ligament organization in the mouse. Arch Oral Biol. 1975;20(2):137-138.

27. Swasty D, Lee JS, Huang JC, et al. Anthropometric analysis of the human mandibular cortical bone as assessed by cone-beam computed tomography. J Oral Maxillofac Surg. 2009;67(3):491-500.

\section{Publish your work in this journal}

Clinical Interventions in Aging is an international, peer-reviewed journal focusing on evidence-based reports on the value or lack thereof of treatments intended to prevent or delay the onset of maladaptive correlates of aging in human beings. This journal is indexed on PubMed Central, MedLine, the American Chemical Society's 'Chemical

\section{Dovepress}

Abstracts Service' (CAS), Scopus and the Elsevier Bibliographic databases. The manuscript management system is completely online and includes a very quick and fair peer-review system, which is all easy to use. Visit http://www.dovepress.com/testimonials.php to read real quotes from published authors.

Submit your manuscript here: http://www.dovepress.com/clinical-interventions-in-aging-journal 